Published in final edited form as:

J Am Chem Soc. 2016 March 16; 138(10): 3298-3301. doi:10.1021/jacs.6b00567.

\title{
Catalytic Asymmetric Total Synthesis of (-)-Actinophyllic Acid
}

\author{
Lingchao Cai, Kui Zhang, and Ohyun Kwon* \\ Department of Chemistry and Biochemistry, University of California, Los Angeles, California \\ 90095-1569, United States
}

\begin{abstract}
Described herein is a catalytic asymmetric total synthesis of (-)-actinophyllic acid, with the key step being a chiral phosphine-catalyzed [3+2] annulation between an imine and an allenoate to form a pyrroline intermediate in $99 \%$ yield and $94 \%$ ee. The synthesis also features CuI-catalyzed coupling between a ketoester and a 2-iodoindole to shape the tetrahydroazocine ring; intramolecular alkylative lactonization; $\mathrm{SmI}_{2}$-mediated intramolecular pinacol coupling between ketone and lactone subunits to assemble the complex skeleton of (-)-actinophyllic acid; and an unprecedented regioselective dehydroxylation.
\end{abstract}

In a search for therapeutic agents for the treatment of cardiovascular disorders, Quinn, Carroll, et al. isolated (-)-actinophyllic acid (1) from the leaves of the tree Alstonia actinophylla growing in Cape York Peninsula, Far North Queensland, Australia (Scheme 1). ${ }^{1}$ (-)-Actinophyllic acid was reported to be a potent inhibitor of the zinc-dependent carboxypeptidase $\mathrm{U}(\mathrm{CPU})$, with an $\mathrm{IC}_{50}$ of $0.84 \mu \mathrm{M}$. CPU is an endogenous inhibitor of fibrinolysis, the breakage of fibrin clots. Consequently, inhibitors of CPU can facilitate fibrinolysis and inhibit the blood clot formation that is a cause of various cardiovascular disorders. ${ }^{2}$ There have not, however, been any subsequent biological studies reported, presumably because of the scarcity of the natural product, due to its low isolation yield $(0.0072 \%) .{ }^{3}$ Therefore, any efficient de novo syntheses of this potent CPU inhibitor should benefit explorations of its biomedical potential.

Structurally, (-)-actinophyllic acid contains the cage-like scaffold of a 1,2,3,5,6,7,8,10aoctahydro-1,7-methanopyrrolo-[1,2-a]azocine, highlighted in red in Scheme 1, with five contiguous stereogenic centers, one of which is a quaternary carbon, bridged by a tetrahydrofuran lactol. ${ }^{4}$ This unprecedented architecture, along with great biomedical potential, has garnered widespread attention from the synthetic community. In 2008, Overman et al. accomplished an elegant total synthesis of ( \pm )-actinophyllic acid through aza-Cope/Mannich cascade strategy (Figure 1). ${ }^{5 a}$ Later, the same group reported a second-

\footnotetext{
*Corresponding Author: ohyun@chem.ucla.edu.

Supporting Information

The Supporting Information is available free of charge on the ACS Publications website at DOI: 10.1021/jacs.6b00567.

Experimental details and data (PDF)

Crystallographic data for 16(CIF)

Crystallographic data for $\mathbf{1 7}$ (CIF)

Notes

The authors declare no competing financial interest.
} 
generation synthesis toward (-)-actinophyllic acid based on diastereoselective coupling between a 2-indole malonate and diacetoxypiperidine. ${ }^{5 b, 6}$ In 2013, Martin's group revealed an alternative synthesis of $( \pm$ )-actinophyllic acid, spotlighting a remarkable cascade reaction between a seven-membered ring dienamine and a tertiary 2 -indolyl acetoxylate. ${ }^{7}$ Contemporarily, the Wood, Taniguchi, Maldonado, and Coldham groups reported their synthetic studies toward this novel monoterpene indole alkaloid. ${ }^{8}$ Previous efforts, and our own experience, exposed that establishing the cis stereochemistry between the $\mathrm{C} 19$ ketone and the $\mathrm{C} 21$ indole substituents on the pyrrolidine ring ( $\mathbf{4}$ to $\mathbf{3}$, Scheme 1 ) is challenging. In both Maldonado's and Coldham's synthetic attempts, intramolecular Mannich reactions between an indole-3-carboxaldehyde and an azocinone resulted in the 1azabicyclo[4.2.1]nonane scaffold with incorrect trans stereochemistry between the C19 ketone and the $\mathrm{C} 21$ indole (actinophyllic acid numbering), presumably due to steric congestion between the indoyl substituent and the adjacent $\mathrm{C} 19$ acyl chain. ${ }^{7 \mathrm{c}, 7 \mathrm{~d}}$ Both Overman and Martin brought this challenge under control through their early stage construction of the indole-fused heptenone (in pink, Figure 1). We, on the other hand, addressed it through intramolecular lactonization (from 7 to 6, Scheme 1). Herein, we report a catalytic asymmetric synthesis of (-)-actinophyllic acid, featuring a chiral phosphinecatalyzed $[3+2]$ annulation between an imine and an electron-deficient allene.

In the retrosynthetic sense, we originally envisioned that (-)-actinophyllic acid could be obtained from the diester $\mathbf{2}$ through Overman's decarboxylation, hydroxymethylation, and lactol formation sequence (Scheme 1). We targeted forming the C15-C16 bond in 2 through oxidative coupling between the malonate and ketone units of intermediate 3 . The 1azabicyclo[4.2.1]nonan-5-one scaffold (in green) of compound $\mathbf{3}$ was to be fashioned from pyrroline 4 via azepinone ring formation. The pyrroline $\mathbf{4}$, in turn, could be assembled through a well-established phosphine-catalyzed [3+2] annulation between an indole imine and an electron-deficient allene. ${ }^{9}$ While reduction of the pyrroline 4 to the 2,3-cissubstituted pyrrolidine was readily accomplished, the formation of the bridged 1azabicycl[4.2.1]nonan-5-one system (in green) proved difficult, due to epimerization at C19, even under mild conditions. ${ }^{10}$ To circumvent these obstacles, we devised an alternative route in which the hexahydroazocine ring would be built first (from 9 to 8). Diastereoselective hydrogenation of the pyrroline should, then, bring the carbonyl groups at C15 and C18 in close proximity to form the azepane ring through pinacol coupling (from 6 to 5). The two carbonyl groups would be brought even closer, we surmised, after intramolecular alkylative lactonization (from $\mathbf{7}$ to $\mathbf{6}$ ). The azocinone ring in compound $\mathbf{8}$ should be accessible through coupling between the indole $\mathrm{C} 2$ atom and the $\mathrm{C} 16$ atom of the $\beta$-ketoester in $\mathbf{9}$, which should be readily preparable from intermediate 4 .

Our synthetic campaign commenced with an exploration of the key [3+2] annulation between benzyl allenoate and the $N$-( $o$-nitrobenzenesulfonyl) ( $o$-nosyl) imine 10, which could be synthesized according to the known procedure from indole 3-carboxaldehyde. ${ }^{9 c}$ Initially, when using $\mathrm{PPh}_{3}$, the desired racemic pyrroline was obtained in $99 \%$ yield after $6 \mathrm{~h}$ (Table 1, entry 1). Our previous studies on the enantioselective synthesis of pyrrolines foretold that the endo-phenyl Kwon [2.2.1] bicyclic phosphine A should produce the desired $(S)$-enantiomer $11 .{ }^{9 \mathrm{c}, \mathrm{d}}$ When we applied $20 \mathrm{~mol} \%$ of phosphine $\mathbf{A}$ to the reaction, the $(S)$ - 
enantiomer was indeed formed in $97 \%$ yield and $75 \%$ ee after $5 \mathrm{~h}$ at room temperature in $\mathrm{CHCl}_{3}$ (entry 2). ${ }^{11,12}$ The more nucleophilic phosphine $\mathbf{B}$ improved the enantioselectivity to $83 \%$ ee. The ee increased further, to $91 \%$, after decreasing the reaction temperature to $0{ }^{\circ} \mathrm{C}$ (entries 3 and 4). Further lowering of the temperature did not improve the ee. ${ }^{13}$ From a mechanistic perspective, we suspected that hydrogen bonding would facilitate the protontransfer steps ${ }^{14}$ and rigidify the transition-state assembly, ${ }^{15}$ thereby improving the enantioselectivity. Among a variety of tested hydrogen-bond donors, we found that phenol and derivatives accelerated the reaction and improved the enantioselectivity. Addition of 20 mol \% phenol or biphenol decreased the reaction time to $2 \mathrm{~h}$, albeit without improving the enantioselectivity (entries 5 and 6). When $20 \mathrm{~mol} \% \mathrm{~s}$-BINOL or $r$-BINOL was used as the additive, the enantioselectivity improved to $94 \%$ without decreasing the yield, with the reaction occurring within $2 \mathrm{~h}$ (entries 7 and 8$).{ }^{15}$

With the annulation product in hand, we attempted to form the hexahydroazocinone ring through oxidative coupling between the ketoester and the $\mathrm{C} 2$ atom of indole. ${ }^{16}$ Quick access to the ketoester $\mathbf{1 3}^{\prime}$ was secured in $92 \%$ yield through deprotection of the $o$-nosyl group, performed with sodium benzenethiolate in $\mathrm{MeCN}$ at room temperature, followed by reaction with ethyl 3-oxopent-4-enoate (Scheme 2). ${ }^{17}$ We examined a list of oxidants, including $\mathrm{Fe}^{3+}$, $\mathrm{Cu}^{2+}, \mathrm{Mn}^{3+}, \mathrm{Co}^{2+}, \mathrm{Ag}^{+}$, and $\mathrm{I}_{2}$, to facilitate the oxidative coupling of the substrates $\mathbf{1 3}^{\prime}$ and $\mathbf{1 3}^{\prime \prime}$, but obtained no fruitful results.

Instead of using an oxidative coupling approach, we anticipated that a redox-neutral coupling reaction between indole 2-iodide and ketoester subunits might give the desired cyclization product $14^{\prime}{ }^{\prime 18}$ Following the procedure used for the synthesis of $\mathbf{1 3}^{\prime}$, the iodoketoester 13 was obtained in $80 \%$ yield over two steps (Scheme 3). Having efficient access to the necessary iodoketoester $\mathbf{1 3}$, several transition-metal catalysts were probed. Pleasingly, subjecting the iodoketoester $\mathbf{1 3}$ to $\mathrm{CuI}$ in DMSO at room temperature yielded (82\%) the desired cyclization product 14, which existed exclusively in its enol form. One recrystallization increased the ee to $99 \% .{ }^{19}$ As far as we know, this CuI-catalyzed coupling is the first between a 2-iodoindole and a ketoester to generate a tetrahydroazocine cycle. ${ }^{18 \mathrm{~d}}$ To our delight, a high pressure of $\mathrm{H}_{2}$ gas over $\mathrm{Pd} / \mathrm{C}$ formed the cis hydrogenation product along with deprotection of the benzyl group in one pot. Exchanging the solvent to DMF and treating the resulting carboxylic acid with chloroiodomethane and $\mathrm{K}_{2} \mathrm{CO}_{3}$ readily manufactured the chloromethyl ester $\mathbf{1 5}$ in $\mathbf{7 8 \%}$ yield for the two steps. After significant experimentation, we found that 40 equiv of $\mathrm{NaI}$ in DMF with $\mathrm{K}_{2} \mathrm{CO}_{3}$ as base furnished the lactone 16 in $35-48 \%$ yield. Although modestly yielded, this alkylative lactonization framed another challenging eight-membered tetrahydrooxocine portion of (-)-actinophyllic acid and set the stage for the final azepane segment, and concomitant tetrahydrofuran part, formation through intramolecular ketone-lactone pinacol coupling. The pinacol coupling strategy departs significantly from the lactol formation approach adopted by Overman and Martin.

Continuing with the synthetic venture, we evaluated the effects of several single-electrontransfer reagents, including $\mathrm{Ti}^{3+}, \mathrm{Li}, \mathrm{Na}$, and $\mathrm{Sm}^{2+}$, on the pinacol coupling. ${ }^{20} \mathrm{Only}_{\mathrm{SmI}}$ combined with 10 equiv of t-BuOH provided the desired coupling product 17, in quantitative yield; its structure was confirmed through X-ray crystallographic analysis. ${ }^{21}$ At this stage, 
the complete heavy atom arrangement of (-)-actinophyllic acid was in place. What remained was regioselective removal of the hindered C15 hydroxyl group from compound $\mathbf{1 7}$.

To this end, we turned our attention to radical dehydroxylation..$^{22}$ The idea was that the thiocarbonate 18, when treated with a tributyltin radical, would undergo homolytic cleavage of the tertiary carbon-oxygen bond preferably, due to electronic differentiation (the rigid multicyclic framework of actinophyllic acid would not allow the necessary stereoelectronic alignment of the lone pair of electrons on the tetrahydrofuran oxygen with the ensuing $\alpha$ radical). The dihydroxy compound $\mathbf{1 7}$ was reacted with thiophosgene in the presence of DMAP at $-15{ }^{\circ} \mathrm{C}$, transforming into the thionocarbonate $\mathbf{1 8}$ in $72 \%$ yield. The standard conditions of $n-\mathrm{Bu}_{3} \mathrm{SnH}$ and AIBN at $90{ }^{\circ} \mathrm{C}$ in toluene worked efficiently to furnish the desired lactol product. Finally, global deprotection, through the effect of aqueous $\mathrm{HCl}$ under microwave heating at $100^{\circ} \mathrm{C}$ for $30 \mathrm{~min}$, furnished (-)-actinophyllic acid hydrochloride in $90 \%$ yield over two steps $\left\{[\alpha]_{589}^{22.8}-175.8^{\circ}(c 1.0, \mathrm{MeOH})\right\}$. The spectral data of our synthetic sample matched those reported in the literature. ${ }^{5}$

In conclusion, we have successfully completed a catalytic asymmetric total synthesis of (-)actinophyllic acid in 13 steps from a known aldehyde in $12.4 \%$ yield. Our synthesis exhibits several salient features: (i) chiral phosphine-catalyzed [3+2] annulation between an allenoate and an indole imine; (ii) CuI-catalyzed coupling between a 2-iodoindole and a ketoester to assemble a hexahydro- $1 H$-azocino[4,3- $b$ ]indole system; (iii) intramolecular alkylative lactonization to form a tetrahydrooxocine ring; (iv) highly efficient pinacol coupling between a ketone and a lactone to form the caged scaffold of (-)-actinophyllic acid; and (v) regioselective removal of a tertiary alcohol by taking advantage of a vicinal hemiketal. Our strategy not only circumvented the difficulties typically associated with forming the correct stereochemistry around the pyrrolidine ring but also resulted in the first enantioselective total synthesis of (-)-actinophyllic acid in which the asymmetric synthesis employs the same starting materials as the racemic synthesis. ${ }^{6}$ Detailed screening of the biological activity of (-)-actinophyllic acid is ongoing.

\section{Supplementary Material}

Refer to Web version on PubMed Central for supplementary material.

\section{Acknowledgments}

We thank the NIH (GM071779) for financial support. This study was supported by shared instrumentation grants from the NSF (CHE-1048804) and the NIH NCRR (S10RR025631). Dedicated to Professor Stuart L. Schreiber on the occasion of his 60th Birthday.

\section{References}

1. (a) Carroll AR, Hyde E, Smith J, Quinn RJ, Guymer G, Forster PI. J Org Chem. 2005; 70:1096. [PubMed: 15675882] Later, Morita et al. isolated (+)-actinophyllic methyl ester from Alstonia pneumatophore in 0.0009\% yield; see:(b) Koyama K, Hirasawa Y, Hosoya T, Hoe T, Chan K, Morita H. Bioorg Med Chem. 2010; 18:4415. [PubMed: 20576577] In 2005, Luo et al. isolated Alstonia scholarine E, which is an ethyl ketal of actinophyllic acid, from Alstonia scholaris in 0.000006\% yield; see:(c) Qin X, Zhao Y, Lunga P, Yang X, Song C, Cheng G, Liu L, Chen Y, Liu Y, Luo X. Tetrahedron. 2015; 71:4372. 
2. (a) Leurs J, Nerme V, Sim Y, Hendriks DJ. J Thromb Haemostasis. 2004; 2:416. [PubMed: 15009457] (b) Polla MO, Tottie L, Nordén C, Linschoten M, Musil M, Trumpp-Kallmeyer S, Aurkurst IR, Ringom R, Holm KH, Neset SM, Sandberg M, Thurmond J, Yu P, Hategan G, Anderson H. Bioorg Med Chem. 2004; 12:1151. [PubMed: 14980627] (c) Leurs J, Hendriks D. Thromb Haemostasis. 2005; 94:417.(d) Marder, VJ.; Aird, WC.; Bennett, JS.; Schulman, S.; White, GC., editors. Hemostasis and Thrombosis: Basic Principles and Clinical Practice. 6th. Lippincott Williams \& Wilkins; Philadelphia: 2013.

3. The natural actinophyllic acid was isolated as a brown gum, but synthetic (-)-actinophyllic acid hydrochloride is a white solid.

4. Taniguchi T, Martin CL, Monde K, Nakanishi K, Berova N, Overman LE. J Nat Prod. 2009; 72:430. [PubMed: 19220031]

5. (a) Martin CL, Overman LE, Rohde JM. J Am Chem Soc. 2008; 130:7568. [PubMed: 18491907] (b) Martin CL, Overman LE, Rohde JM. J Am Chem Soc. 2010; 132:4894. [PubMed: 20218696]

6. Having failed to introduce chirality through catalytic asymmetric heteroarylation of piperidone with indole (a strategy employed in the earlier racemic synthesis), Overman's key transformation was based on diastereoselective heteroarylation of piperidine diacetoxylate. The enantioriched piperidine diol derivative was synthesized through Noyori's asymmetric hydrogenation.

7. (a) Granger BA, Jewett IT, Butler JD, Hua B, Knezevic CE, Parkinson EI, Hergenrother PJ, Martin SF. J Am Chem Soc. 2013; 135:12984. [PubMed: 23972114] (b) Granger BA, Jewett IT, Butler JD, Martin SF. Tetrahedron. 2014; 70:4094. [PubMed: 24882888]

8. (a) Vaswani RG, Day JJ, Wood JL. Org Lett. 2009; 11:4532. [PubMed: 19810762] (b) Zaimoku H, Taniguchi T, Ishibashi H. Org Lett. 2012; 14:1656. [PubMed: 22369137] (c) Galicia IZ, Maldonado LA. Tetrahedron Lett. 2013; 54:2180.(d) Mortinmer D, Whiting M, Harrity JPA, Jones S, Coldham I. Tetrahedron Lett. 2014; 55:1255.(e) Meketa, ML. PhD Thesis. Pennsylvania State University; Dec. 2008 Part One: Total Syntheses Of Ageladine A; Part Two: Studies Directed Towards a Total Synthesis of Actinophyllic Acid.

9. (a) Zhu XF, Henry CE, Kwon O. Tetrahedron. 2005; 61:6276.(b) Andrews IP, Kwon O. Org Synth. 2011; 88:138.(c) Andrews IP, Kwon O. Chem Sci. 2012; 3:2510. [PubMed: 22798981] (d) Henry CE, Xu Q, Fan YC, Martin TJ, Belding L, Dudding T, Kwon O. J Am Chem Soc. 2014; 136:11890. [PubMed: 25099350] For reports on Lu's original allene-imine [3 + 2] annulation, see:(e) Xu Z, Lu X. Tetrahedron Lett. 1997; 38:3461.(f) Xu Z, Lu X. J Org Chem. 1998; 63:5031.

10. A weak base (e.g., $\mathrm{K}_{2} \mathrm{CO}_{3}$ ), a weak acid (e.g., $p$-TSA), or neutral conditions (e.g., $\mathrm{NaBH}_{3} \mathrm{CN}$ or $\mathrm{PhSNa}$ ) could induce the epimerization.

11. Both chiral phosphines are commercially available from Sigma-Aldrich. Phosphine A: catalog no. L512397; phosphine B: catalog no. L512478.

12. After removing the crystalline racemic pyrroline 11, we could enrich the ee of the mother liquid up to $94 \%$.

13. See the Supporting Information for further details regarding optimization of the conditions.

14. Xia Y, Liang Y, Chen Y, Mang M, Jiao L, Huang F, Liu S, Yu Z. J Am Chem Soc. 2007; 129:3470. [PubMed: 17319666]

15. (a) Shi M, Chen LH. Chem Commun. 2003; 1310(b) Han X, Zhong F, Wang Y, Lu Y. Angew Chem Int Ed. 2012; 51:767.(c) Yao W, Dou X, Lu Y. J Am Chem Soc. 2015; 137:54. [PubMed: 25401753]

16. (a) Paquette LA, Bzowej EI, Branan BM, Stanton KJ. J Org Chem. 1995; 60:7277.(b) Baran PS, Richter JM, Lin DW. Angew Chem Int Ed. 2005; 44:609.c) Magolan J, Kerr MA. Org Lett. 2006; 8:4561. [PubMed: 16986950] (d) Richter JM, Whitefield BW, Maimone TJ, Lin DW, Castroviejo MP, Baran PS. J Am Chem Soc. 2007; 129:12857. [PubMed: 17900115] (e) Chen P, Cao L, Tian W, Wang X, Li C. Chem Commun. 2010; 46:8436.(f) Zi W, Xie W, Ma D. J Am Chem Soc. 2012; 134:9126. [PubMed: 22616754] (g) Oisaki K, Abe J, Kanai M. Org Biomol Chem. 2013; 11:4569. [PubMed: 23739720] (h) Jiang Q, Sheng W, Tian M, Tang J, Guo C. Eur J Org Chem. 2013; 2013:1861.(i) Wang H, Guo LN, Duan XH. Chem Commun. 2013; 49:10370.(j) Matsubara T, Takahashi K, Ishihara J, Hatakeyama S. Angew Chem Int Ed. 2014; 53:757.For a brief review, see: (k) Csaky AG. Plumet Chem Soc Rev. 2001; 30:313.(1) Guo F, Clift MD, Thomson RJ. Eur J Org Chem. 2012; 2012:4881. 
17. Barcan GA, Patel A, Houk KN, Kwon O. Org Lett. 2012; 14:5388. in this paper PhSK was generated from $\mathrm{KH}$ and thiophenol, this approach worked well for our reactions. PhSNa could be obtained at lower cost by mixing thiophenol and $\mathrm{NaOH}$ and drying in a high-vacuum oven. [PubMed: 23039026]

18. (a) Hamann BC, Beare NA, Hartwig JF. J Am Chem Soc. 1997; 119:12382.(b) Hennessy EJ, Buchwald SL. Org Lett. 2002; 4:269. [PubMed: 11796067] (c) Xie X, Cai G, Ma D. Org Lett. 2005; 7:4693. [PubMed: 16209512] (d) Coste A, Toumi M, Wright K, Razafimahaleo V, Couty F, Marrot J, Evano G. Org Lett. 2008; 10:3841. [PubMed: 18681449] Recent reviews on enolate coupling, see:(e) Culkin DA, Hartwig JF. Acc Chem Res. 2003; 36:234. [PubMed: 12693921] (f) Johansson CCC, Colacot TJ. Angew Chem Int Ed. 2010; 49:676.(g) Bellina F, Rossi R. Chem Rev. 2010; 110:1082. [PubMed: 19610600]

19. Because we could not identify conditions for the separation of the two enantiomers of compound 14, we proceeded to compound 15 to determine the enantiomeric excess. See the SI for more details.

20. (a) Auer E, Gossinger E, Graupe M. Tetrahedron Lett. 1997; 38:6577.(b) Molander GA, Wolfe CN. J Org Chem. 1998; 63:9031.(c) Yamamoto Y, Matsumi D, Itoh K. Chem Commun. 1998; 34:875. (d) Liu Y, Zhang Y. Tetrahedron Lett. 2001; 42:5745.(e) Hasegawa E, Kentaro O, Tanikawa N, Nakamura M, Iwaya K, Hoshi T, Suzuki T. Tetrahedron Lett. 2006; 47:7715.(f) Ge HM, Zhang LD, Tan RX, Yao ZJ. J Am Chem Soc. 2012; 134:12323. [PubMed: 22799615] (g) Frey G, Luu HT, Bichovski P, Feurer M, Streuff D. Angew Chem Int Ed. 2013; 52:7131.(h) Bichovski P, Haas TM, Kratzert D, Streuff J. Chem-Eur J. 2015; 21:2339. [PubMed: 25476744] For more recent reviews on $\mathrm{SmI}_{2}$, see:(i) Edmonds DJ, Johnston D, Procter D. J Chem Rev. 2004; 104:3371.(j) Nicolaou KC, Ellery SP, Chen JS. Angew Chem Int Ed. 2009; 48:7140.

21. More than 10 equiv of $\mathrm{t}-\mathrm{BuOH}$ slowed down the reaction and necessitated the use of increased amounts of $\mathrm{SmI}_{2}$, and $<10$ equiv of $t$-BuOH resulted in formation of the following rearrangement side product:

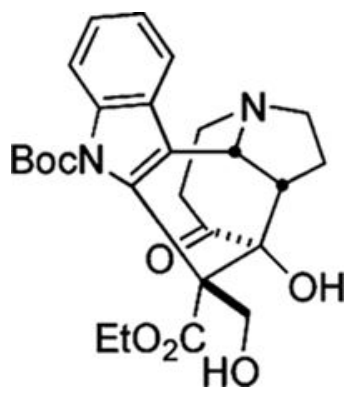

22. (a) Emmer G, Roth SW. Tetrahedron. 1992; 48:5861.(b) Myers AG, Tom NJ, Fraley ME, Cohen SB, Madar DJ. J Am Chem Soc. 1997; 119:6072.(c) Brüggemann M, McDonald AI, Overman LE, Rosen MD, Schwink L, Scott JP. J Am Chem Soc. 2003; 125:15284. [PubMed: 14664560] (d) Nicolaou KC, Sun YP, Korman H, Sarlah D. Angew Chem Int Ed. 2010; 49:5875. 
Overman

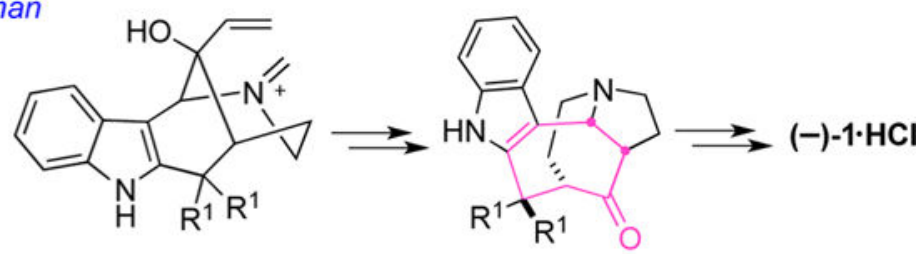

Martin

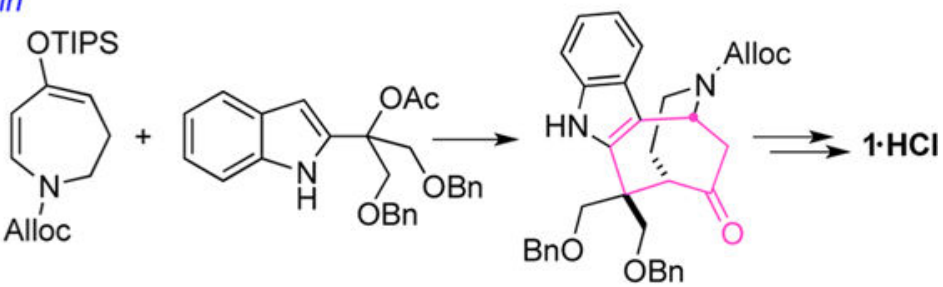

Maldonado and Coldham

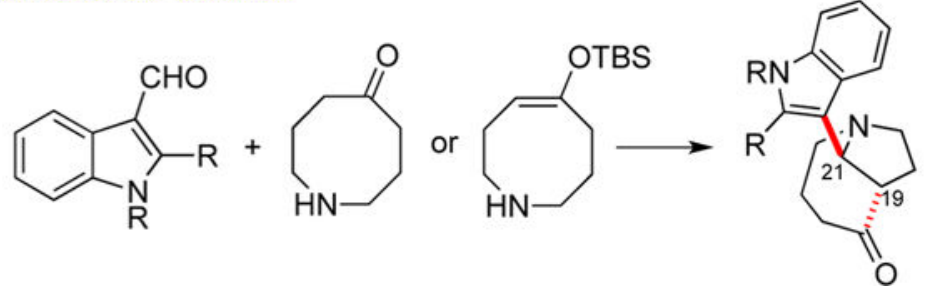

Figure 1.

Key steps in previous attempts toward actinophyllic acid. 

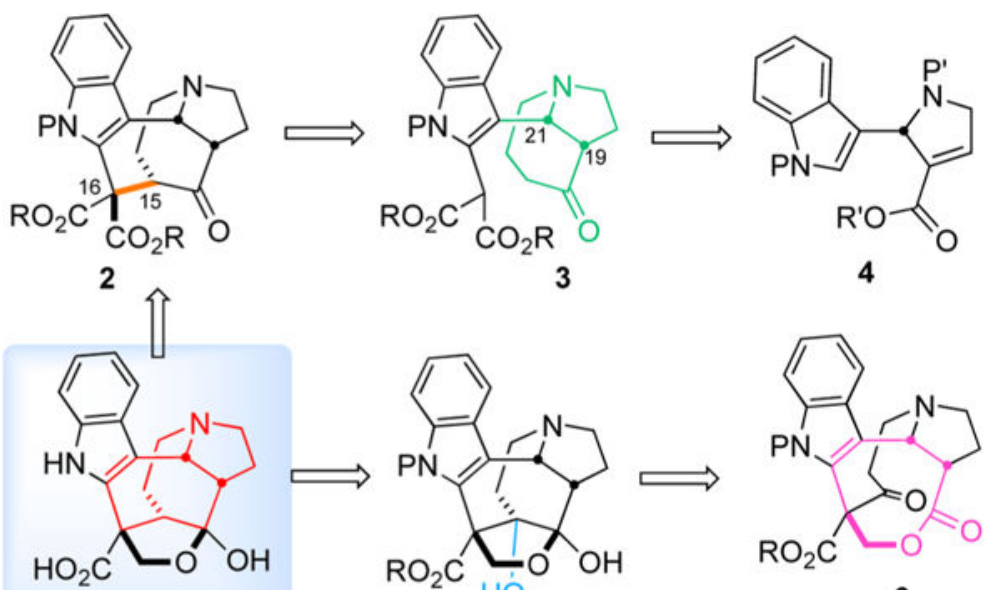

(-)-Actinophyllic acid

1
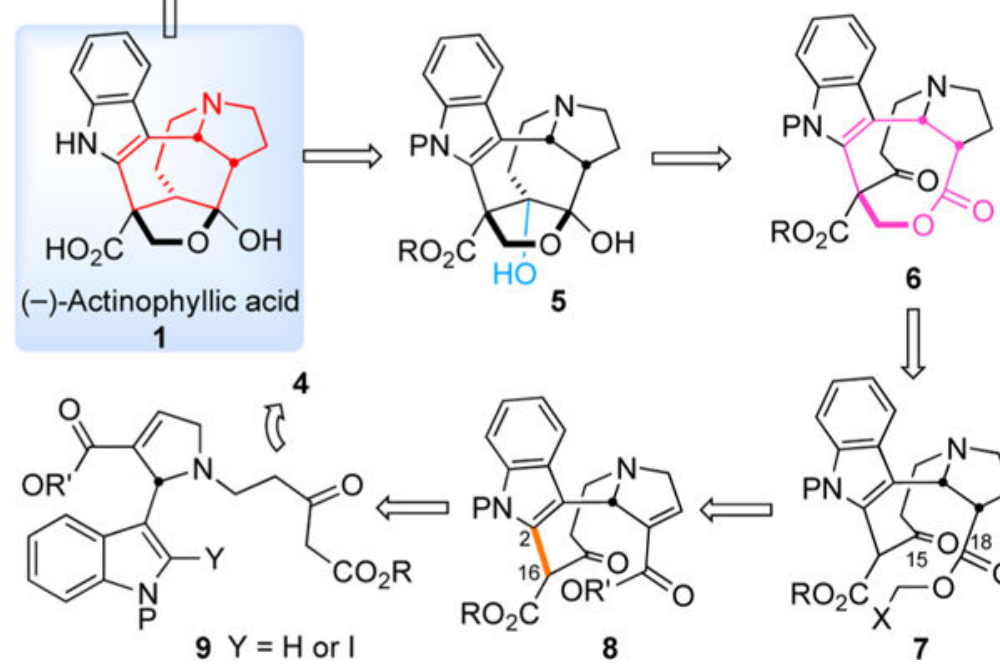


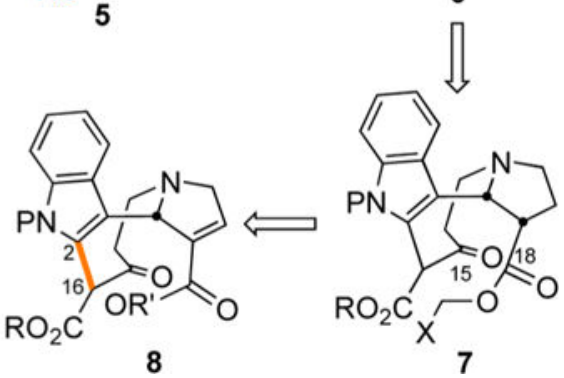

Scheme 1.

Retrosynthesis of (-)-Actinophyllic Acid 


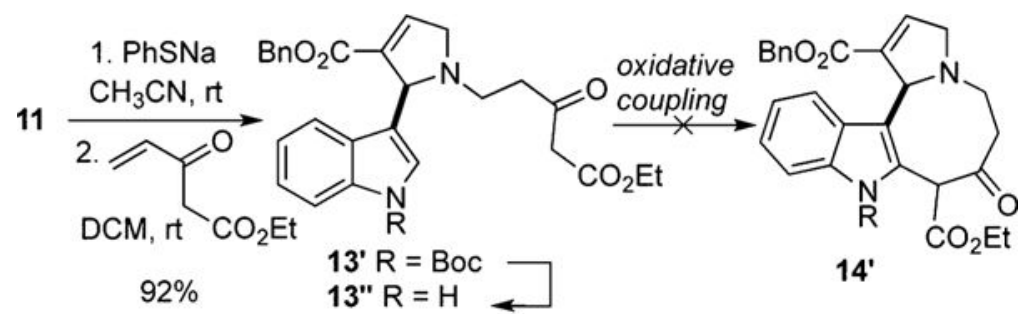

TFA, DCM, $80 \%$

Scheme 2.

Attempted Oxidative Coupling 


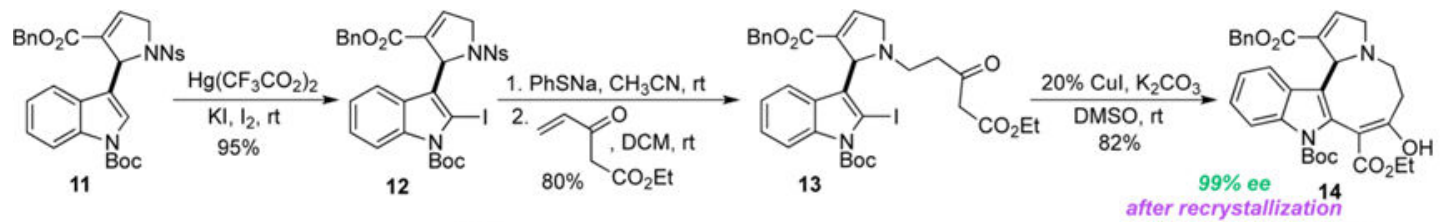

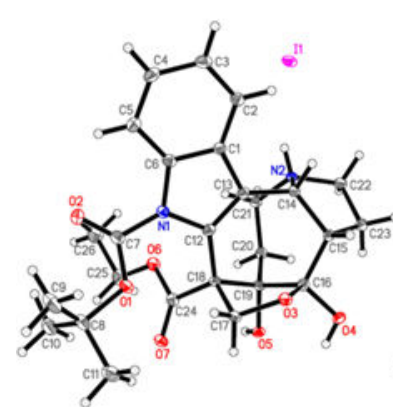

ORTEP structure of $\mathbf{1 7}$

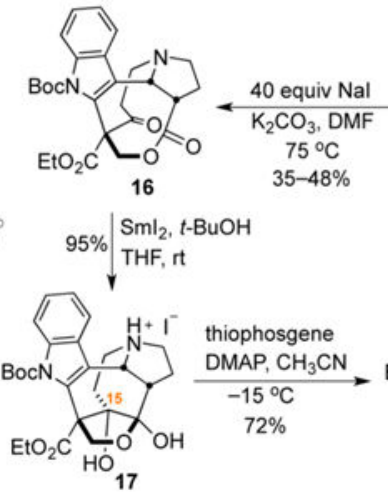

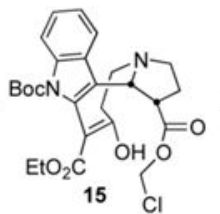
after recrystallization
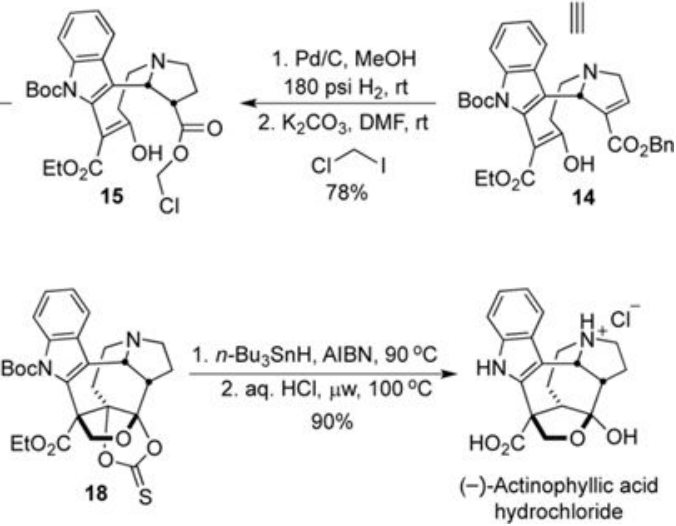

Scheme 3.

Synthesis of (-)-Actinophyllic Acid Hydrochloride 

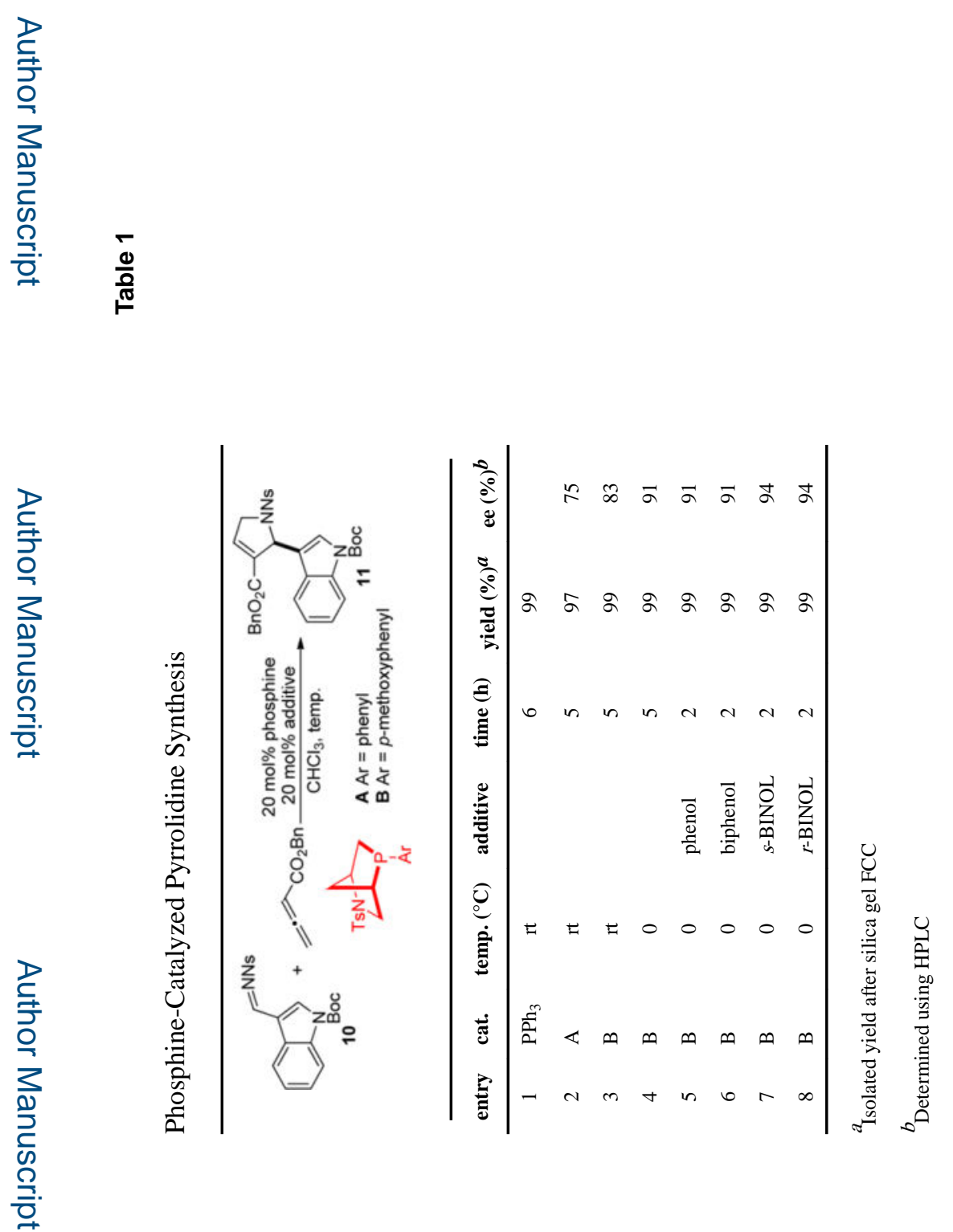

J Am Chem Soc. Author manuscript; available in PMC 2017 March 16. 